\title{
SELEÇÃO DE ÁRVORES MATRIZES DE Schizolobium parahyba var. amazonicum (Huber ex. Ducke) Barneby NO ESPÍRITO SANTO
}

\author{
Adelson Lemes da Silva Júnior ${ }^{1}$ \\ Lucimara Cruz de Souza ${ }^{2}$ \\ Paulo Henrique de Souza ${ }^{3}$ \\ William Macedo Delarmelina ${ }^{4}$ \\ Fábio Demolinari de Miranda ${ }^{5}$ \\ Marcos Vinicius Winckler Caldeira ${ }^{6}$
}

Resumo: O objetivo desse trabalho foi selecionar indivíduos da espécie Schizolobium parahyba var. amazonicum (Huber ex. Ducke) Barneby, localizados em uma área de floresta plantada no Espírito Santo, para serem utilizados como matrizes constituindo um futuro pomar de sementes, que possam subsidiar plantios comerciais na obtenção de madeira. Para isto, foi realizado o inventário da área, onde foram coletados valores de diâmetro à altura do peito (DAP) em todos os indivíduos e para a altura total ( $\mathrm{Ht}$ ) foi realizado cálculos de estimativa. O delineamento foi em blocos casualizados, onde foi realizada a análise de variância (ANOVA) e aplicado o Teste de Tukey para determinação dos tratamentos a serem utilizados na seleção. Foram selecionadas 171 árvores baseadas nos valores médios de 15,59 cm de DAP e 12,03 $m$ de $\mathrm{Ht}$ dos tratamentos escolhidos, além da avaliação quanto a forma do fuste, condição fitossanitária, vigor, disposição na paisagem e condição de luminosidade. As variáveis DAP e Ht se mostraram favoráveis para realização da seleção das árvores e as outras características avaliadas servirão para criação do pomar de sementes.

Palavras-chave: Inventário florestal; Paricá; Pomar de sementes.

\footnotetext{
${ }^{1}$ Mestre em Genética e Melhoramento/UFES, Brasil. E-mail: adelsonlemes@yahoo.com.br.

2 Mestranda em Genética e Melhoramento/UFES, Brasil. E-mail: lucimaracruz15@hotmail.com.

3 Doutorando em Ciências Florestais/UFES, Brasil. E-mail: engflorestalphs@gmail.com.

4 Doutorando em Ciências Florestais/UFES, Brasil. E-mail: williamdm@hotmail.com.

5 Prof. Doutor em Genética e Melhoramento/UFES, Brasil. E-mail: fademolinari@yahoo.com.br.

${ }^{6}$ Prof. Doutor em Ciências Florestais/UFES, Brasil. E-mail: mvwcaldeira@gmail.com.
} 